\title{
Internet use, risks and online behaviour: the view of Internet users with intellectual disabilities and their caregivers
}

Esther Chiner, Department of Health Psychology, University of Alicante, Spain

Marcos Gómez-Puerta, Department of Developmental Psychology and Teaching, University of Alicante, Spain

M. Cristina Cardona-Moltó, Department of Health Psychology, University of Alicante, Spain

\section{Correspondence}

Esther Chiner, Departamento de Psicología de la Salud, Edificio de Ciencias Sociales, Universidad de Alicante, Crta. de San Vicente del Raspeig, s/n, 03690, Sant Vicent del Raspeig, Spain (E-mail: esther.chiner@ua.es). Phone number: +34 965909664

\section{Acknowledgments}

This research was supported by Grant No. GRE 13-05 awarded by the University of Alicante, Spain. We would also like to thank the collaboration of all the members of the APSA association who participated in this study.

Chiner, E., Gómez-Puerta, M. y Cardona-Moltó, M. C. (2017). Internet use, risks and online behaviour: the view of internet users with intelectual disabilities and their caregivers. British Journal of Learning Disabilities, 45(3), 190-197. doi: 10.1111/bld.12192 


\title{
Accessible Summary
}

- Going online is important because we can learn, meet people, and get info. But some actions by others or by ourselves can be harmful.

- We wanted to find out how people with intellectual disabilities in Spain go online and the problems they have using it.

- We asked 77 adults with intellectual disabilities and 68 caregivers to answer questions about how people with intellectual disabilities use the Web.

- We found that people with intellectual disabilities prefer smartphones to go online, and that they listen to music, watch videos or chat with friends online.

- We also found out that sometimes they have problems such as receiving insults or being blocked.

Keywords Intellectual disability, family, practical skills, social interaction

\begin{abstract}
Background: Internet offers opportunities to people with intellectual disabilities but it also involves some risks. The aim of this study was to explore these issues considering caregivers and people with intellectual disabilities' perspectives.
\end{abstract}

Materials and Methods: A descriptive, cross-sectional study was conducted. The sample consisted of 77 adults with intellectual disabilities and 68 caregivers from a Spanish service provider organisation.

Results: Compared to previous research, findings show an increasing use of electronic devices such as smartphones and the Internet by people with intellectual disabilities. 
Some online risks (e.g. being insulted, being threatened, someone using their personal information) and undesirable behaviours of this group (e.g. insulting, threatening or flirting with someone who did not want to) were also identified. Differences between the responses of people with intellectual disabilities and their caregivers were found with regard to people with intellectual disabilities' online behaviour.

Conclusions: It is important to design, validate and implement strategies to promote risk management and positive risk-taking actions for people with intellectual disabilities.

\section{Introduction}

The access to ICT, and especially to the Internet, has contributed to significant changes in the way people socialise and access to information, services and work. Technologies have promoted a better quality of life and better life outcomes not only for the general population (Palmer, Wehmeyer, Davies, \& Stock, 2012) but also for certain groups such as individuals with intellectual disability, favouring their full participation and inclusion in the society (Chadwick, Wesson, \& Fullwood, 2013).

The concept of 'digital inclusion' refers to the possibility of having the right access, skills, motivation and trust to confidently go online (Department for Culture, Media, and Sport, 2014) and it has become a priority for countries and international agencies. For instance, the European Disability Strategy 2010-2020 focuses specifically on the need to improve the accessibility of services and products for all citizens, especially those with disabilities, pointing out the field of ICT as a priority. To accomplish this objective, the European Digital Agenda has set up specific actions to achieve e-inclusion in the European Union (Ministry of Industry, Energy, and Tourism, 
2013).

\section{Use of electronic devices and the Internet}

The use of electronic devices such as computers, tablets and smartphones is perceived as a particularly promising area for disabled people for the important range of training and functional options offered (Molin, Sorbring, \& Löfgren-Martenson, 2015). Furthermore, Internet access is an aspect of particular interest for those with intellectual disabilities as it can be beneficial in many ways (e.g. social interaction, participation, learning). However, some studies show a significantly lower use of electronic devices by disabled people (Kaye, 2000), especially those with intellectual disabilities (Carey, Friedman, \& Bryen, 2005; Chadwick et al., 2013; Gutiérrez \& Martorell, 2011). In the case of Internet use, Wehmeyer, Smith, \& Palmer (2004) identify as specific barriers: (a) limited access to computers, (b) lack of cognitive accessibility of the software, (c) the complexity of operating systems, and (d) the amount of reading involved in their use. Furthermore, the families of these people may also encounter difficulties in the use of the Internet (Blackburn \& Read, 2005).

In the American context, Carey et al. (2005) interviewed 83 adults with intellectual disabilities showing that the technologies most commonly used were regular phone, computers, video games, mobile phone, and the Internet. The latter was generally used to find information on travel, social events, online games or to read the news. Moreover, in the European context, the Statistical Indicators for Benchmarking the Information Society Project (SIBIS) showed that (a) only 33\% of disabled people in the European Union used a computer regularly, compared to $60 \%$ of the general population, and (b) only $29 \%$ used the Internet compared to $50 \%$ of nondisabled people (Empirica, 2003). The survey conducted in the Netherlands by Didden et al. (2009) with 
114 students with disabilities attending a special education school revealed that most students owned a mobile phone and had Internet access at home. The most common activities on the Internet were Microsoft Network (MSN), downloading music, pictures and films, playing online games, and sending and receiving emails. In the Spanish context, Gutiérrez \& Martorell (2011) surveyed 156 individuals with intellectual disabilities from a disability organisation and reported that almost $90 \%$ of the participants had a mobile phone, but only $50 \%$ of them had Internet access at home. This is a significantly lower proportion than the Dutch sample that found that almost all the participants (97\%) had access to the Internet at home. In the Spanish sample, from those having Internet connection, $56.4 \%$ did not use this service regularly. Despite the relevance of previous research, the rapid changes in technology demand further studies to examine the evolution of ICT use among people with intellectual disabilities. Technologies have developed a great deal in the past years becoming more accessible and easier to use for everyone. However, there is a lack of recent literature addressing these issues and more evidence about the patterns of use of technologies, and particularly the Internet, is needed.

\section{Risks on the Internet}

Internet access has potential risks for individuals who are perceived as particularly vulnerable to abuse, such as children and people with intellectual disabilities (Chadwick, Quinn, \& Fullwood, 2017; Livingstone, Haddon, Görzig, \& Ólafsson, 2011). For instance, a recent study conducted by Author (2016) with 40 students with intellectual disabilities examined the potential limitations of people with intellectual disabilities to deal with untrustworthy information sources on the Internet. Findings showed that people with intellectual disabilities differed from the control 
groups in the extent to which they identified the reliability and trustworthiness of those sources of information.

For the purposes of this study, we understand online risks as the problems that people with intellectual disabilities encounter on the Internet. Some of the risks to which they may be exposed are: (a) inappropriate content (e.g. Web pages with selfharm, violence, racism content), (b) an unwanted contact (e.g. grooming, sexual harassment, cyberbullying), or (c) the improper conduct of the person in his use of the Internet (Livingstone et al., 2011). In response to these risks, recommendations for training in the safe and responsible use of the Internet have been made (e.g. Buijs, Boot, Shugar, Fung, \& Bassett, 2017) and easy reading documents have been developed for the prevention of risks in the use of the Internet and social networks (e.g. FEVAS, 2015).

Despite the growing literature concerning Internet use in the general population (e.g. Jones, Mitchell, \& Finkelhor, 2012; Livingstone et al., 2011), little is known about the potential risks for individuals with intellectual disabilities (Normand \& Sallafranque-St-Louis, 2016). Research has usually focused on the use of specific technical aids (Carey et al., 2005) and only a few studies addressed the use of the Internet by people with intellectual disabilities. In this regard, the study conducted by Didden et al. (2009) explored the types, prevalence and associated variables of cyberbullying among students with intellectual and developmental disabilities. Findings showed that $4-9 \%$ of the participants reported bullying or victimization of bullying frequently. This study also found significant relationships between cyberbullying and intelligence quotient, type of disorder, self-esteem, and frequency of computer use. Wells \& Mitchell (2014), in a study carried out in the United States with a sample of 
1,560 also concluded that people receiving special education services use the Internet less frequently than those without such services and, therefore, seem to be at less risk of online victimization. However, when using the Internet, they are more likely to report this fact. The aforementioned studies focus on students receiving special education services and these samples may not reflect the Internet experiences of adults with intellectual disabilities who are already out of school. The present study tries to address this situation focusing on this population.

Finally, the recent study conducted in England by Chadwick, Quinn, \& Fullwood (2017) concluded that nondisabled people perceive the benefits and risks of the Internet to be greater for people with intellectual disabilities than for the general population, suggesting the presence of some misconceptions and misunderstandings. Authors also lay out whether the perceived online risks translate into actual risks when people with intellectual disabilities go online. Our study tries to respond to this question by surveying, both people with intellectual disabilities and caregivers, about the actual online behaviours of people with intellectual disabilities and the subsequent risks of Internet use.

\section{The role of caregivers}

Palmer et al. (2012) suggest that caregivers are the primary supports for technology use by individuals with intellectual disabilities. The bond between them and those with intellectual disabilities can be so close and strong that it could even restrict the development of self-determination and independence (Löfgren-Mårtenson, 2004). Caregivers often feel responsible for their safety showing different forms of control and/or restrictions (Löfgren-Mårtenson, 2008). They can see people with intellectual disabilities as particularly vulnerable and exposed to certain risks and, therefore, they 
try to protect them by restricting Internet use (Molin et al., 2015). Additionally, the Internet is, in many cases, a private activity and caregivers may be unaware of what is taking place when individuals with intellectual disabilities go online, having different perceptions about the nature of Internet use and the activities that people with intellectual disabilities carry out when they gain online access. Research concerning caregivers' views about the use of the Internet by people with intellectual disabilities is also scarce. The study conducted by Molin et al. (2015) provides insight into caregivers' perspectives on the concerns and the benefits of the Internet. Findings show that teachers consider the Internet full of opportunities, especially for interactive purposes, although they worry about students getting into problematic and dangerous situations. Similarly, parents are in general positive about the Internet and, despite their concerns, they consider that its advantages outweigh the inconveniences. The 'positive risk-taking' approach supports this idea and considers that enabling people with intellectual disabilities to have a greater control of their lives and to enhance their wellbeing may also involve some risks (Seale, 2014). However, instead of avoiding or ignoring the risks, people with intellectual disabilities and their supporters should address them through a shared decision-making and negotiation process (McConkey \& Smyth, 2003).

Further studies must be conducted to explore the nature of Internet use by people with intellectual disabilities and how the potential risks can be managed to offer them the best opportunities for participation and inclusion in a secure online environment. In this context, the main purpose of this study was to explore Internet use, risks and online behaviour among adults with intellectual disabilities. Information was collected from people with intellectual disabilities and from their caregivers. Specifically, the current study addresses the following objectives: (a) to describe the use of electronic devices 
and the Internet by people with intellectual disabilities, (b) to explore Internet risks, and (c) to examine undesirable online behaviour.

\section{Materials and Method}

\section{Participants}

Participants in this study were a convenience sample of 77 adults with intellectual disabilities and 68 caregivers from a provincial non-profit association that provides support to people with intellectual and developmental disabilities, from early childhood to adulthood, through a variety of services. Specifically, the sample of adults with intellectual disabilities was drawn from the sheltered vocational training programmes which are oriented to adults with mild to moderate intellectual disability (American Psychiatric Association, 2013).

Sixty-four percent of the participants with intellectual disabilities $(n=49)$ were male and $28(36 \%)$ were female. Their age ranged between 18 and 51 years $(M=25.31$, $S D=8.1)$. Caregivers consisted of 68 family members $(n=40)$ and staff members $(n=$ $28) ; 39 \%(n=26)$ were male and $41(61 \%)$ were female, and their age ranged between 26 and 85 years $(M=51.03, S D=13.43)$. Regarding family members, $80 \%$ of the participants $(n=32)$ were parents of people with intellectual disabilities, $13 \%(n=5)$ were legal guardians and $7 \%$ were siblings $(n=3)$. The years of working experience in the association of the staff members ranged from one to $28(M=12.86, S D=8.19)$.

\section{Instruments}

The questionnaire was designed specifically for this study using the work developed by the European network EU Kids Online (Livingstone et al., 2011) as a framework. 
Questions were drawn from the original instrument and were adapted to our audience, ensuring that the items were appropriate for adults with and without intellectual disabilities. Three versions of the instrument were designed, one for people with intellectual disabilities, one for family members and one for professionals. Differences between these versions are limited to some sociodemographic data and wording.

Initial versions were sent to a panel of experts on ICT and intellectual disability from three different universities and a service organisation $(n=11)$ to assess the content validity of the instruments with the result of changes in some items to make them more understandable. A second panel of experts $(n=5)$ assessed the reviewed instruments obtaining a content validity index (CVI) of 1 for the people with intellectual disabilities and family members' versions and a CVI of .98 for the professionals' version (Lawshe, 1975).

The final instrument was comprised of 13 items in four sections: (a) demographic data (e.g. age, gender, years of working experience), (b) electronic devices and Internet use (i.e. devices used, frequency of use, type of activities on the Internet), (c) Internet risks (i.e., type of problems encountered on the Internet), and (d) undesirable online behaviour (i.e., online behaviour engaged by people with intellectual disabilities that could harm other Internet users). Participants had to respond to multiple choice and dichotomous questions (yes and no).

\section{Procedure}

A descriptive study was conducted using a cross-sectional survey design. It was carried out in full accordance with the ethical principles of The Declaration of Helsinki (World Medical Association, 2016) and the Convention on Human Rights and Biomedicine (Council of Europe, 1997), and with the approval of the ethics committee of the 
University XX which funded this project. Participants were recruited by contacting the association where one of the researchers work. After the association consented to participate, questionnaires were distributed as follows: (a) questionnaires were sent by postal mail to family members; (b) the professionals' version was handed out personally; and (c) the version for people with intellectual disabilities was handed out personally by a research team member who was present to help with the completion of the survey, guiding the reading of the questions and solving doubts individually. Family members and professionals were asked to return the completed questionnaires after two weeks. The questionnaire included a cover letter informing them about the aims of the study and inviting them to participate in it. Participants were also asked to give their written consent ensuring their willingness to take part in the study. Family and staff members did not have access to people with intellectual disabilities responses and anonymity and confidentiality was guaranteed at all times. Response rates varied widely among groups. The lowest response rate was found among family members (14\%) and the highest one was found among staff members (56\%). The response rate of participants with intellectual disabilities was $25 \%$. A low response rate among people with intellectual disabilities was basically due to the lower number, than initially expected, of groups in the association that finally consented to participate. On the other hand, the factors that led to a low response rate among caregivers, especially family members, could be various. First, some letters could have included incorrect postal addresses. Second, parents' reluctance to participate and researchers failing to highlight the importance of the study and to involve family members in it. These questions should be addressed in future research.

\section{Results}


Findings are displayed according to the three objectives raised: use of electronic devices and the Internet, Internet risks, and undesirable online behaviour. Information is presented simultaneously for both groups (people with intellectual disabilities and caregivers, respectively). Differences between their responses were analysed using the phi coefficient $(\phi)$. This coefficient measures the degree of association between two dichotomous variables (i.e. people with intellectual disabilities/caregivers and responses yes/no). Coefficients were considered significant at the .05 level $(p<.05)$. Responses of both audiences always refer to activities and behaviour demonstrated by people with intellectual disabilities on the Internet.

\section{Use of electronic devices and the Internet}

The smartphone is the device mostly used by people with intellectual disabilities to gain online access. Table 1 shows that $90 \%$ of the participants with intellectual disabilities and $83 \%$ of the caregivers stated that they use the smartphone more than the laptop (69\% vs $80 \%)$, the computer (61\% vs $81 \%)$ and the tablet (57\% vs $64 \%)$. Differences between groups were found only for the computer $(\phi=-.204, p<.05)$. Caregivers reported a significantly higher use of this device by people with intellectual disabilities than those with intellectual disabilities actually did. They mostly use computers (42\% vs $55 \%$ ), laptops (43\% vs 57\%), tablets (42\% vs 39\%) and Smart TVs (36\% vs 30\%) at home, while smartphones are used both at home and outside the home (64\% vs $61 \%)$.

Table 1 Use of electronic devices by participants with intellectual disabilities 


\begin{tabular}{|c|c|c|c|c|c|c|}
\hline \multirow[b]{2}{*}{ Electronic device } & \multicolumn{2}{|c|}{$\begin{array}{l}\text { People with } \\
\text { intellectual } \\
\text { disabilities } \\
\quad(n=77)\end{array}$} & \multicolumn{2}{|c|}{$\begin{array}{c}\text { Caregivers } \\
(n=51)\end{array}$} & \multirow[b]{2}{*}{$\phi$} & \multirow[b]{2}{*}{$p$} \\
\hline & $n$ & $\%$ & $n$ & $\%$ & & \\
\hline Computer & 47 & 61 & 41 & 81 & -.204 & .021 \\
\hline Laptop & 53 & 69 & 34 & 80 & -.110 & .228 \\
\hline Smartphone & 69 & 90 & 42 & 83 & .105 & .236 \\
\hline Tablet & 44 & 57 & 28 & 64 & -.064 & .484 \\
\hline Smart TV & 33 & 43 & 15 & 43 & .000 & 1.000 \\
\hline
\end{tabular}

A high proportion of the participants with intellectual disabilities used the smartphone daily (74\% vs $68 \%$ ). However, we found a discrepancy between people with intellectual disabilities and caregivers' responses regarding the daily use of computers (25\% vs $49 \%)$, laptops ( $27 \%$ vs $37 \%)$ and tablets ( $21 \%$ vs $33 \%)$. As shown in Table 2, significant differences were found between groups $(p<.05)$ with medium to large effect sizes. Caregivers reported a greater use of these devices by people with intellectual disabilities than people with intellectual disabilities did.

Table 2 Frequency of Internet use by participants with intellectual disabilities 


\begin{tabular}{|c|c|c|c|c|c|c|c|c|}
\hline \multirow[b]{2}{*}{$\begin{array}{c}\text { Electronic } \\
\text { device }\end{array}$} & \multicolumn{2}{|c|}{ People with ID } & \multicolumn{2}{|c|}{ Caregivers } & \multirow[b]{2}{*}{$d f$} & \multirow[b]{2}{*}{$t$} & \multirow[b]{2}{*}{$p$} & \multirow[b]{2}{*}{$\begin{array}{c}\text { Cohen's } \\
d\end{array}$} \\
\hline & $M$ & $S D$ & $M$ & $S D$ & & & & \\
\hline Computer & 2.12 & 1.26 & 2.88 & 1.31 & 124 & -3.236 & .002 & 0.59 \\
\hline Laptop & 2.45 & 1.25 & 2.88 & 1.23 & 117 & -1.785 & .077 & 0.34 \\
\hline Smartphone & 3.45 & 1.04 & 3.27 & 1.20 & 126 & .898 & .371 & 0.16 \\
\hline Tablet & 2.03 & 1.23 & 2.55 & 1.40 & 113 & -2.052 & .042 & 0.39 \\
\hline Smart TV & 1.97 & 1.32 & 1.84 & 1.31 & 106 & .480 & .632 & 0.09 \\
\hline
\end{tabular}

Findings also show significant differences with respect to the activities people with intellectual disabilities engage in when using the Internet (Table 3). For instance, participants with intellectual disabilities and caregivers reported that the former mostly use the Internet for listening to music ( $84 \%$ vs $78 \%$ ), watching videos (77\% vs $75 \%$ ), chatting with friends (70\% vs $82 \%$ ) and reading or writing on social networks (66\% vs 73\%). However, respondents with intellectual disabilities reported a significantly greater use of the Internet for reading the newspaper $(\phi=.215, p<.05)$, reading other things $(\phi=.237, p<.01)$, writing e-mails $(\phi=.244, p<.01)$ and watching TV $(\phi=$ $.212, p<.05)$ than caregivers stated. On the contrary, caregivers reported that people with intellectual disabilities frequently use the Internet for chatting with strangers $(\phi=-$ $.322, p<.01)$ and playing online games $(\phi=-.203, p<.05)$.

Table 3 Activities undertaken on the Internet by participants with intellectual disabilities 


\begin{tabular}{|c|c|c|c|c|c|c|}
\hline \multirow[b]{2}{*}{ Activity } & \multicolumn{2}{|c|}{$\begin{array}{l}\text { People with } \\
\text { intellectual } \\
\text { disabilities } \\
\quad(n=77)\end{array}$} & \multicolumn{2}{|c|}{$\begin{array}{l}\text { Caregivers } \\
(n=51)\end{array}$} & \multirow[b]{2}{*}{$\phi$} & \multirow[b]{2}{*}{$p$} \\
\hline & $n$ & $\%$ & $n$ & $\%$ & & \\
\hline Watching videos & 59 & 77 & 38 & 75 & .024 & .785 \\
\hline Reading newspapers & 19 & 25 & 4 & 8 & .215 & .015 \\
\hline Reading other things & 25 & 33 & 6 & 12 & .237 & .007 \\
\hline Chatting with friends & 54 & 70 & 42 & 82 & -.138 & .118 \\
\hline Chatting with strangers & 10 & 13 & 21 & 41 & -.322 & .000 \\
\hline $\begin{array}{l}\text { Reading / writing on social } \\
\text { networks }\end{array}$ & 51 & 66 & 37 & 73 & -.037 & .450 \\
\hline Writing e-mails & 35 & 46 & 11 & 22 & .244 & .006 \\
\hline Buying things & 5 & 7 & 1 & 2 & .105 & .235 \\
\hline Playing online games & 37 & 48 & 35 & 69 & -.203 & .022 \\
\hline Watching films & 41 & 53 & 20 & 39 & .138 & .120 \\
\hline Watching TV & 25 & 33 & 7 & 14 & .212 & .017 \\
\hline Listening to music & 64 & 84 & 40 & 78 & .076 & .388 \\
\hline
\end{tabular}

\section{Internet risks}

All respondents with intellectual disabilities reported having some kind of problem when they went online. The most common were being blocked on a group or activity on the Internet (48\%), being told unpleasant things or insulted (46\%), being threatened $(35 \%)$ or receiving sexual photos or videos that they did not want to receive $(35 \%)$. Some of them reported that someone had tried to flirt with them against their will (43\%) and that someone had used their password without their consent $(36 \%)$. On the other hand, $39 \%$ of the caregivers ignored whether participants with intellectual disabilities had encountered some kind of problem on the Internet. From those caregivers who were 
aware of these problems, they identified being insulted (66\%), being told unpleasant things $(60 \%)$ and being blocked on a group or activity on the Internet $(50 \%)$ as the most common issues. As shown in Table 4, significant differences were found only in one problem: $16 \%$ of the caregivers thought that someone had wanted to meet participants with intellectual disabilities in person as against $39 \%$ of the respondents with intellectual disabilities who reported this experience $(\phi=.228, p<.05)$.

Table 4 Internet risks for participants with intellectual disabilities

\begin{tabular}{|c|c|c|c|c|c|c|}
\hline \multirow[b]{2}{*}{ Risk } & \multicolumn{2}{|c|}{$\begin{array}{l}\text { People with } \\
\text { intellectual } \\
\text { disabilities } \\
\quad(n=77)\end{array}$} & \multicolumn{2}{|c|}{$\begin{array}{c}\text { Caregivers } \\
(n=32)\end{array}$} & \multirow[b]{2}{*}{$\phi$} & \multirow[b]{2}{*}{$p$} \\
\hline & $n$ & $\%$ & $n$ & $\%$ & & \\
\hline Do not know $(n=51)$ & - & - & 20 & 39 & & \\
\hline $\begin{array}{l}\text { Someone flirting with them against } \\
\text { their will }\end{array}$ & 33 & 43 & 8 & 25 & .168 & .080 \\
\hline $\begin{array}{l}\text { Being asked for information / } \\
\text { photos }\end{array}$ & 25 & 33 & 11 & 34 & -.018 & .847 \\
\hline $\begin{array}{l}\text { Someone wanting to meet them in } \\
\text { person }\end{array}$ & 30 & 39 & 5 & 16 & .228 & .017 \\
\hline Being insulted & 35 & 46 & 21 & 66 & -.184 & .055 \\
\hline Being told unpleasant things & 35 & 46 & 19 & 60 & -.127 & .186 \\
\hline $\begin{array}{l}\text { Being blocked on a group or } \\
\text { activity on the Internet }\end{array}$ & 37 & 48 & 16 & 50 & -.018 & .853 \\
\hline Being threatened & 27 & 35 & 12 & 37 & -.023 & .809 \\
\hline Receiving sexual photos / videos & 27 & 35 & 10 & 31 & .037 & .702 \\
\hline $\begin{array}{l}\text { Someone wanting to sell them } \\
\text { things online }\end{array}$ & 16 & 21 & 4 & 13 & .097 & .309 \\
\hline Using personal information & 24 & 31 & 8 & 25 & .062 & .520 \\
\hline Losing money online & 9 & 12 & 6 & 19 & -.093 & .330 \\
\hline Having their password used by & 28 & 36 & 6 & 19 & .173 & .071 \\
\hline
\end{tabular}


others

\section{Undesirable online behaviour}

Participants with intellectual disabilities rarely reported engaging in undesirable behaviour when going online. The most frequent behaviour of this kind was blocking someone else on a group or activity $(55 \%, n=42)$. Less than a quarter of the respondents reported saying unpleasant things to others (21\%), insulting (20\%), threatening $(17 \%)$ or flirting with someone who did not want to $(14 \%)$. Other kinds of behaviour such as asking for private information or pictures, showing inappropriate Web pages or videos to others, sending sexual pictures or videos, or using someone else's personal information or password, represented less than $10 \%$ of the responses of the participants with intellectual disabilities (see Table 5).

Caregivers reported that people with intellectual disabilities had behaved inappropriately more often than respondents with intellectual disabilities actually stated. For instance, statistically significant differences were found between people with intellectual disabilities and caregivers' responses regarding the following behaviours: wanting to meet in person someone who actually did not want to (4\% vs $24 \%$ ), insulting others (20\% vs $68 \%)$, saying unpleasant things to others (21\% vs $64 \%)$, threatening someone ( $17 \%$ vs $48 \%$ ), sending sexual pictures or videos to someone without his or her consent (5\% vs 32\%), encouraging others to visit inappropriate Web pages (4\% vs $36 \%$ ) or using someone else's personal information (5\% vs 40\%). Still, $49 \%$ of caregivers reported not being aware of these online behaviours engaged by people with intellectual disabilities.

Table 5 Undesirable online behaviour of participants with intellectual disabilities 


\begin{tabular}{|c|c|c|c|c|c|c|}
\hline \multirow[b]{2}{*}{ Online behaviour } & \multicolumn{2}{|c|}{$\begin{array}{l}\text { People with } \\
\text { intellectual } \\
\text { disability } \\
\quad(n=77)\end{array}$} & \multicolumn{2}{|c|}{$\begin{array}{l}\text { Caregivers } \\
(n=25)\end{array}$} & \multirow[b]{2}{*}{$\phi$} & \multirow[b]{2}{*}{$p$} \\
\hline & $n$ & $\%$ & $n$ & $\%$ & & \\
\hline Do not know $(n=49)$ & - & - & 24 & 49 & & \\
\hline $\begin{array}{l}\text { Flirting with someone who did not } \\
\text { want to }\end{array}$ & 11 & 14 & 6 & 24 & -.112 & .257 \\
\hline $\begin{array}{l}\text { Asking for private information / } \\
\text { photos }\end{array}$ & 6 & 8 & 5 & 20 & -.169 & .087 \\
\hline $\begin{array}{l}\text { Wanting to meet someone in } \\
\text { person when he / she did not want } \\
\text { to }\end{array}$ & 3 & 4 & 6 & 24 & -.305 & .002 \\
\hline Insulting & 15 & 20 & 17 & 68 & -.450 & .000 \\
\hline Saying unpleasant things & 16 & 21 & 16 & 64 & -.401 & .000 \\
\hline $\begin{array}{l}\text { Blocking someone on a group or } \\
\text { activity on the Internet }\end{array}$ & 42 & 55 & 11 & 44 & .091 & .359 \\
\hline Threatening someone & 13 & 17 & 12 & 48 & -.311 & .002 \\
\hline $\begin{array}{l}\text { Sending sexual photos / videos } \\
\text { without the other's consent }\end{array}$ & 4 & 5 & 8 & 32 & -.358 & .000 \\
\hline $\begin{array}{l}\text { Encouraging others to visit certain } \\
\text { pages }\end{array}$ & 3 & 4 & 9 & 36 & -.429 & .000 \\
\hline $\begin{array}{l}\text { Showing Web pages / videos about } \\
\text { harming others }\end{array}$ & 5 & 7 & 0 & 0 & .129 & .191 \\
\hline $\begin{array}{l}\text { Showing Web pages / videos about } \\
\text { how to cause harm }\end{array}$ & 2 & 3 & 0 & 0 & .081 & .416 \\
\hline $\begin{array}{l}\text { Showing Web pages / videos about } \\
\text { self-harming }\end{array}$ & 4 & 5 & 0 & 0 & .115 & .245 \\
\hline $\begin{array}{l}\text { Showing Web pages / videos that } \\
\text { disparaged others }\end{array}$ & 4 & 5 & 1 & 4 & 0.24 & .810 \\
\hline $\begin{array}{l}\text { Showing Web pages / videos about } \\
\text { drugs }\end{array}$ & 4 & 5 & 0 & 0 & .115 & .245 \\
\hline $\begin{array}{l}\text { Using personal information } \\
\text { without the other's consent }\end{array}$ & 4 & 5 & 10 & 40 & -.435 & .000 \\
\hline Making someone lose money & 4 & 5 & 0 & 0 & .115 & .245 \\
\hline
\end{tabular}


online

$\begin{array}{llllllll}\text { Using someone else's password } & 4 & 5 & 2 & 8 & -.051 & .605\end{array}$

\section{Discussion}

The present study aimed to explore the patterns of Internet use among people with intellectual disabilities, as well as to identify the potential risks and undesirable behaviours they engage in when going online. In line with previous studies, findings show an increasing use of electronic devices by people with intellectual disabilities, especially smartphones (Didden et al., 2009; Gutiérrez \& Martorell, 2011). Internet access is also increasing. We noticed a higher prevalence of people with intellectual disabilities going online than that reported in other studies (e.g. Carey et al., 2005; Gutiérrez \& Martorell, 2011). The development and easy access to certain tools have facilitated Internet access to disabled people. In our study, the most common activities were related to leisure and participating in social networks. Again, these results are similar to those found in the studies carried out by Carey et al. (2005) and Didden et al. (2009). The Internet has become a place for social interaction where people with intellectual disabilities can benefit from the very nature of the virtual environment. Its visual anonymity helps them feel more confident and give them the opportunity to participate in different social networks, which may not be possible in an offline environment (Chadwick et al., 2013).

However, Internet can also be a space with risks and people with intellectual disabilities may be especially vulnerable to those risks. The general population perceives that both benefits and risks are greater for people with intellectual disabilities, considering that this population is at more risk of being bullied, threatened or harassed 
online (Chadwick et al., 2017). Our findings tend to confirm these perceptions showing a slightly higher prevalence of the online risks than those reported by Didden et al. (2009). The study also identified some undesirable online behaviour that may directly affect other Internet users and that requires further investigation. Participants with intellectual disabilities and caregivers recognised that the former also engaged in behaviours such as harassing or bullying others. Yet, the prevalence of these behaviours was lower than the problems encountered. The lack of the right social skills to engage in online social interactions may underlie these behaviours. The Internet can be a place full of opportunities for people with intellectual disabilities only if they know how to use it properly. Hence, it is important to train them in the particular environment of the Internet. People with intellectual disabilities need to learn how to manage the inherent risks of the Internet as well as how to address the social interactions in a way that respects others' space. More evidence about these issues will help to design training programmes that focus not only on the acquisition of digital competence but also on the social skills that are needed to establish satisfactory online interactions. On the other hand, findings show a similar trend in Internet use with the trend encountered with the general population (e.g. Jones et al., 2012; Livingstone et al., 2011). Therefore, some of the programmes about Internet safety and literacy that are being developed for nondisabled people could be adapted for its implementation with adults with intellectual disabilities. Further comparative studies should be carried out to find evidence about similarities and differences in patterns of Internet use between both populations.

Some discrepancies were found between people with intellectual disabilities and caregivers' responses. We would expect that people with intellectual disabilities will not report all the actions they carry out when they go online and, therefore, caregivers will have wrong perceptions about the use of the Internet by this group. However, caregivers 
need to be more aware of the potential benefits and risks of this technology and the impact that the Internet can have on the lives of people with intellectual disabilities. This could be achieved by providing people with intellectual disabilities with the right tools to gain online access and help them make their own decisions (Seale, 2014). The present results underpin the importance of designing and implementing educational strategies for the prevention of online risks. These strategies should be oriented in two ways. Firstly, towards disabled people incorporating these strategies within their own training plans for literacy and digital competence. Secondly, towards caregivers in order to (a) strengthen their ability to prevent or to identify problems on the Internet and (b) equip them with strategies for early intervention.

Some limitations of the present study must be pointed out. First, the crosssectional nature of this investigation and the sample size do not allow to make causal inferences nor generalising the findings to the entire population of people with intellectual disabilities and caregivers. Results of this study only reflect the perceptions of a small group of people from a single association and their responses may not represent those from other organisations. The particularities of this association (e.g. participating in literacy and digital competence programmes) may determine the perceptions participants had about the issues addressed in this study. An extension of this study to other service provider organisations is advisable. Second, the low response rate of family members needs to be addressed in future research. Parents seem to be reluctant to participate in this kind of study. As researchers, we need to be more accessible and be able to explain to family members the relevance of these investigations if we want to achieve a greater inclusion of people with intellectual disabilities in the digital arena. Third, people with intellectual disabilities and caregivers' responses may not truly reflect their actual behaviours since they could have 
provided socially desirable responses, especially people with intellectual disabilities with regard to their online behaviour. Also, caregivers reported what they were aware of, which not always corresponds with the actual behaviours of people with intellectual disabilities, as seen in this study. However, the inclusion of caregivers' perspectives is still important since they are interested parties in the digital inclusion of people with intellectual disabilities as they facilitate their use of technologies (Seale, 2014). Fourth, it is possible that the impairments related to the intellectual disability may affect their ability to accurately answer some questions of the survey (Wells \& Mitchell, 2014). However, the possibility of gathering information directly from the source will contribute to a better understanding of the online needs, interests, and actual behaviours of people with intellectual disabilities and will help to address these issues properly.

\section{Conclusion}

The Internet has provided multiple benefits and advantages to people with intellectual and other disabilities while introducing challenges and drawbacks. Our study showed that people with intellectual disabilities are not only exposed to the risks of using the Internet, but they also engage in undesirable online behaviours that must be addressed. Literacy and training programmes should be directed to help people with intellectual disabilities to understand the importance of the Internet, the consequences of its use and the way to manage the potential problems encountered in an online environment. In addition, further research is needed in order to gain insight into the circumstances under which the Internet is being used. Future investigations should take a step forward and address not only the use of electronic devices and the Internet by people with intellectual disabilities, but also identify the type of behaviours they undertake and the way they use technology. Only a deeper knowledge of these issues will help to make the 
right decisions to promote an inclusive, responsible and safe use of the Internet by people with intellectual disabilities.

\section{References}

American Psychiatric Association. (2013). Diagnostic and Statistical Manual of Mental Disorders (5th ed.). Arlington, VA: American Psychiatric Publishing.

Blackburn, C., \& Read, J. (2005). Using the Internet? The experiences of parents of disabled children. Child: Care, Health \& Development, 31(5), 507-515.

Buijs, P. C. M., Boot, E., Shugar, A., Fung, W. L. A., \& Bassett, A. S. (2017). Internet Safety Issues for Adolescents and Adults with Intellectual Disabilities. Journal of Applied Research in Intellectual Disabilities, 30(2), 416-418. doi:10.1111/jar.12250

Carey, A. C., Friedman, M. G., \& Bryen, D. N. (2005). Use of electronic technologies by people with intellectual disabilities. Mental Retardation, 43(5), 322-333. doi:10.1352/0047-6765(2005)43[322:UOETBP]2.0.CO;2

Chadwick, D. D., Quinn, S., \& Fullwood, C. (2017). Perceptions of the risks and benefits of Internet access and use by people with intellectual disabilities. British Journal of Learning Disabilities, 45(1), 21-31. doi:10.1111/bld.12170

Chadwick, D. D., Wesson, C., \& Fullwood, C. (2013). Internet access by people with intellectual disabilities: inequalities and opportunities. Future Internet, 5, 376397. doi:10.3390/fi5030376

Council of Europe. (1997). Convention on Human Rights and Biomedicine. Retrieved from http://www.coe.int/en/web/bioethics/oviedo-convention

Department for Culture, Media, and Sport. (2014). Government Digital Inclusion Strategy. 
https://www.gov.uk/government/publications/government-digital-inclusion$\underline{\text { strategy/government-digital-inclusion-strategy }}$

Didden, R., Scholte, R. H. J., Korzilius, H., De Moor, J. M. H., Vermeulen, A., O'Reilly, M., . . L Lancioni, G. E. (2009). Cyberbullying among students with intellectual and developmental disability in special education settings. Developmental

Neurorehabilitation,

12(3), 146-151. doi:10.1080/17518420902971356

Empirica. (2003). Benchmarking social inclusion in the Information Society in Europe and the US. Retrieved from http://www.empiririca.biz/sibis

Federación Vasca de Asociaciones en Favor de las Personas con Discapacidad Intelectual [FEVAS]. (2015). Internet y redes sociales. Por un uso seguro y responsable. Retrieved from http://fevas.org/?wpfb_dl=81

Gutiérrez, P., \& Martorell, A. (2011). People with intellectual disability and ICTs. Comunicar, 18(36), 173-180. doi:10.3916/C36-2011-03-09

Jones, L. M., Mitchell, K. J., \& Finkelhor, D. (2012). Trends in Youth Internet Victimization: Findings From Three Youth Internet Safety Surveys 2000-2010. Journal of Adolescent Health, 50(2), 179-186. doi:http://dx.doi.org/10.1016/j.jadohealth.2011.09.015

Kaye, H. S. (2000). Computer and Internet use among people with disabilities. Washington, DC: Department of Education, National Institute on Disability and Rehabilitation Research.

Lawshe, C. H. (1975). A quantitative approach to content validity. Personnel Psychology, 28, 563-575. doi:10.1111/j.1744-6570.1975.tb01393.x 
Livingstone, S., Haddon, L., Görzig, A., \& Ólafsson, K. (2011). Risks and Safety on the Internet: the perspective of European children. Full findings. LSE, Londres: EU Kids Online.

Löfgren-Mårtenson, L. (2004). "May I?" About sexuality and love in the new generation with intellectual disabilities. Sexuality \& Disability, 22(3), 29-39.

Löfgren-Mårtenson, L. (2008). Love in cyberspace. Swedish young people with intellectual disabilities and the Internet. Scandinavian Journal of Disability Research, 10(2), 125-138. doi:http://dx.doi.org/10.1080/15017410701758005

McConkey, R., \& Smyth, M. (2003). Parental perceptions of risks with older teenagers who have severe learning difficulties contrasted with the young people's views and experiences. Children \& Society, 17(1), 18-31. doi:10.1002/chi.725

Ministry of Industry, Energy, and Tourism. (2013). Agenda Digital para España. Febrero de 2013. http://www.agendadigital.gob.es/agendadigital/recursos/Recursos/1.\%20Versión \%20definitiva/Agenda_Digital_para_Espana.pdf.

Molin, M., Sorbring, E., \& Löfgren-Martenson, L. (2015). Teachers' and parents' views on the Internet and social media usage by pupils with intellectual disabilities. Journal of Intellectual Disabilities, $\quad$ 19(1), 22-33. doi:10.1177/1744629514563558

Normand, C. L., \& Sallafranque-St-Louis, F. (2016). Cybervictimization of Young People With an Intellectual or Developmental Disability: Risks Specific to Sexual Solicitation. Journal of Applied Research in Intellectual Disabilities, 29(2), 99-110. doi:10.1111/jar.12163

Palmer, S. B., Wehmeyer, M. L., Davies, D. K., \& Stock, S. E. (2012). Family members' reports of the technology use of family members with intellectual and 
developmental disabilities. Journal of Intellectual Disability Research, 56(4), 402-414. doi:10.1111/j.1365-2788.2011.01489.x

Salmerón, L., Gómez, M., \& Fajardo, I. (2016). How students with intellectual disabilities evaluate recommendations from internet forums. Reading and Writing, 29(8), 1653-1675. doi:10.1007/s11145-016-9621-4

Seale, J. (2014). The role of supporters in facilitating the use of technologies by adolescents and adults with learning disabilities: a place for positive risk-taking. European Journal of Special Needs Education, 29(2), 220-236. doi:http://dx.doi.org/10.1080/08856257.2014.906980

Wehmeyer, M. L., Smith, S. J., \& Palmer, S. B. (2004). Technology use by students with intellectual disabilities: an overview. Journal of Special Education Technology, 19(4), 7-21. doi:10.1177/016264340401900402

Wells, M., \& Mitchell, K. J. (2014). Patterns of Internet Use and Risk of Online Victimization for Youth With and Without Disabilities. The Journal of Special Education, 48(3), 204-213. doi:10.1177/0022466913479141

World Medical Association. (2016). Ethical principles for medical research involving $\begin{array}{lll}\text { human } & \text { subjects. } & \text { Retrieved }\end{array}$ http://www.wma.net/en/30publications/10policies/b3/ 